\title{
An Update on Behavioural Interventions for Improving Adherence with Continuous Positive Airway Pressure in Adults
}

\author{
Angela L. D'Rozario ${ }^{1,2,3}$ • Yael Galgut ${ }^{1}$ • Delwyn J. Bartlett ${ }^{1,4}$
}

Published online: 11 August 2016

(C) Springer International Publishing AG 2016

\begin{abstract}
Obstructive sleep apnoea (OSA) is a common sleep disorder which if left untreated results in considerable physical and psychological co-morbidity and mortality. With the development of continuous positive airway pressure (CPAP), an effective treatment was available to counteract the partial and complete airway closures, hypoxia and sleep fragmentation. Technological advances in CPAP devices improved the interface between machine and man, reduced noise levels and improved many aspects of the treatment process. Yet, with all these advancements over the last 35 years, adherence to CPAP remains low. There are a number of underlying factors in the poor uptake and discontinuation of treatment. Previous CPAP adherence interventions are discussed along with behavioural programmes which have emerged in the last 3 years. Of importance are the insights gained from emerging qualitative research
\end{abstract}

This article is part of the Topical Collection on Behavioral Therapy

Delwyn J. Bartlett

delwyn.bartlett@sydney.edu.au

Angela L. D'Rozario

angela.drozario@sydney.edu.au

Yael Galgut

elle.galgut@sydney.edu.au

$1 \quad$ Sleep \& Circadian Research Group, Woolcock Institute of Medical Research, The University of Sydney, PO Box M77, Missenden Road, Sydney, NSW 2050, Australia

2 Sydney Local Health District, Camperdown, Sydney, NSW, Australia

3 School of Psychology, Faculty of Science, Brain and Mind Centre and Charles Perkins Centre, The University of Sydney, Sydney, NSW, Australia

4 Sydney Medical School, The University of Sydney, Sydney, NSW, Australia in this area to enable a better understanding of patient perceptions and how these continue to impact on adherence rates.

Keywords Adherence - Compliance - Obstructive sleep apnoea $\cdot$ Behavioural interventions · Psycho-education . Psychosocial factors $\cdot$ Co-morbidity $\cdot$ Cognitive behavioural therapy

\section{Introduction}

Obstructive sleep apnoea (OSA) is a common sleep disorder with overall population estimates ranging from 2 to $7 \%[1,2]$, increasing in middle-aged populations to $9 \%$ of women and $24 \%$ of men [3]. These figures are continually evolving. Higher estimates of obesity in the Western world are associated with a higher incidence of OSA with estimates of 14 $55 \%$ [4], whilst increasing age further increases OSA prevalence. The rise in obesity coupled with an increasingly ageing population further pressurises our healthcare systems and highlights the need for effective treatment of this disorder. Continuous positive airway pressure (CPAP) therapy is still perceived as the "gold standard" treatment of OSA; however, uptake and adherence remain low. We have divided this paper into three sections to aid the reader in this review.

Section I: we discuss the consequences of untreated OSA, the effectiveness and dose response of CPAP usage, along with the management of side effects and daily difficulties encountered, and we explore more recent qualitative research in this area from the perspective of our patients.

Section II: this section predominantly deals with the various behavioural treatment interventions used to increase adherence and includes psychosocial interventions, 
cognitive behavioural therapy (CBT), motivational interviewing (MI), standard care and educational programmes, combined treatments and then finally the role of partners in these interventions.

Section III: we explore the behavioural interventions in the last 3 years and their impact on the uptake and adherence to CPAP therapy and finally discuss the overall results.

\section{Section I}

\section{Negative Consequences of Untreated OSA}

Left untreated, OSA has long-term serious adverse outcomes. In men, there is evidence of an all-cause mortality relationship with adverse cardiovascular outcomes, of which OSA severity is a constant predictor $[5,6]$. In OSA, chronic sleep fragmentation, intermittent hypoxia and changes in sympathetic activity are associated not only with negative cardiovascular outcomes [7] but also with diabetes [8], increases in inflammatory markers and metabolic syndrome [9], and depression [10]. Other negative psychosocial consequences include poor road safety [11, 12], greater absenteeism at work [13] and a lessdiscussed but potential negative impact on relationships and libido at home $[14,15]$.

\section{Treatment with CPAP}

CPAP [16] reduces physical, psychological and neurocognitive co-morbidity by eliminating apnoeas/ hypopnoeas thereby stabilising oxygen saturation levels [17]. More recently, CPAP has been shown to potentially have a protective role in decreasing the hypothalamic-pituitaryadrenal axis activity [18] and stabilising but not decreasing the inflammatory cytokine interleukin (IL)-6 [19]. Increased nightly usage of CPAP or a dose response is associated with improved neurocognitive function and better mood [20-22]. However, even after 35 years and considerable technological advances including improved devices and objective assessment, adherence to CPAP treatment remains low. The dropout rate ranges from 5 to $50 \%$ in the first week to 6 months [23] with critical time points such as the experience of CPAP in the first 3 days predicting long-term use [24]. Earlier research [25-27] established adherence to CPAP at approximately $4.7 \mathrm{~h}$ use per night or $4 \mathrm{~h}$ on $70 \%$ of the nights used.

\section{Dose Response to CPAP}

In a review by Sawyer and colleagues [28], the $>4$-h CPAP adherence level was explored in relation to hours of use, duration of treatment and normalisation of symptoms and subjective/objective sleepiness and neurocognitive function. At least $5 \mathrm{~h}$ of CPAP use was associated with improved subjective and objective sleepiness [29]; better scores on the Functional Outcomes Sleep Questionnaire (FOSQ) occurred with greater CPAP use [20], whilst $7 \mathrm{~h}$ use resulted in optimal improvement of symptoms but with a ceiling effect [22]. Normalisation of subjective sleepiness occurred with $4 \mathrm{~h}$ of CPAP in severe OSA, but required $6 \mathrm{~h}$ for objectively measured improvements [22]. Antic and colleagues [20] found improvements in subjective sleepiness with 3 months of CPAP, but normalisation was not consistently related to either hours of usage or objectively measured sleepiness. In relation to neurocognitive function, verbal memory and executive function improved with $>4 \mathrm{~h}$ of CPAP [20], whereas Zimmerman and colleagues found memory was eight times more likely to normalise with $6 \mathrm{~h}$ of CPAP compared with $\leq 2 \mathrm{~h}$ [30]. The 4-h CPAP adherence level is associated with improvements in subjective sleepiness and some components of neurocognitive function but with wide variability in individual responses. Some CPAP, even an hour, is better than no CPAP [31], whilst increasing time using CPAP on a nightly basis, and across time, is most likely to elucidate better longterm outcomes.

\section{Difficulties and Side Effects with Using CPAP}

Most individuals learning to use their CPAP experience considerable difficulties with side effects (mask interface, machine pressure, flexible pressure, leaks and mouth/throat dryness and use of humidifiers), not necessarily impacting adherence $[23,32]$. Technological improvements to reduce side effects are continually being tested. Heated humidification did not improve adherence in OSA patients with nasopharyngeal complaints (NPC) compared with a low-risk group [33]. Subjective sleepiness was improved with high CPAP adherence in both groups (NPC 5.5 vs. $4.6 \mathrm{~h}$ ) suggesting a considerable benefit regardless of NPC. Other factors include initial acceptance of a type of mask at titration. Switching to a different mask was associated with a 7.2 odds ratio of giving up CPAP [34] even though there was a $61 \%$ resolution of physical difficulties with the new mask. Women were more likely to change masks which may relate to most masks being originally designed for men.

Claustrophobia is one side effect associated with reduced adherence. Individuals using CPAP for $<2 \mathrm{~h}$ were twice as likely to have higher scores on the fear and avoidance scale used to assess claustrophobia [35]. Edmonds and colleagues [36] identified $63 \%$ of OSA sufferers had some degree of claustrophobia after their CPAP titration study, affecting females more than males and negatively impacting on adherence rates at 1 week and 1 month. One of the ongoing issues with CPAP adherence is how day-to-day difficulties and physical symptoms are treated, with an assumption they are 
addressed in standard clinical care. There appears to be considerable variation in content and effectiveness of standard care which will be explored in more detail in the educational section.

\section{Qualitative Research in CPAP Usage}

Qualitative research is useful in defining subjectively how a disorder (OSA) or its proposed treatment (CPAP) impacts on the individual. Dickerson and Akhu-Zaheya [37] explored the experience of managing this relatively invasive technology. Twenty OSA patients described the first 3 months of using their CPAP via written or spoken text using a phenomenological approach, before CPAP titration and again at 1 and 3 months post-CPAP initiation. Six themes identified from the patients' feedback were (1) trouble using CPAP-noise factors for the patient and/or partner, mask leakage, dryness, runny nose, condensation and face marks with a key message that for many, these outcomes were unexpected; (2) needing to persist through the initial and recurring frustration - related to the lack of appropriate problem-solving information and lack of accessible support especially from home-care companies; (3) difficulty recognising subtle improvements-over time and in any co-morbidities such as pain, asthma and depression, with any improvements often obscured unless family members commented on changes; (4) accessing help and problem solving - significant variability in help available; and (5) becoming part of lifestyle or abandoning CPAP-a trade-off between not liking to use it but feeling better the next day. Abandonment of the device often occurred when the balance between CPAP difficulties and the pluses of adherence was compromised. Positive feedback from family and friends enabled persistence, which most likely has a selfefficacy component, which will be discussed in more detail.

Crawford and colleagues [38] proposed an integration of psychology with medicine as CPAP adherence is multifaceted. This approach requires reciprocity with the "biological processes, the psychological experience and social behaviours" or a biopsychosocial model. The biomedical model is descriptive encompassing age, gender, body mass index and race/ethnicity; plus OSA severity: apnoea-hypopnoea index (AHI), respiratory disturbance index and daytime symptoms such as sleepiness; plus CPAP pressure, mask used and any associated side effects. The psychological model combines coping style, mood, stress and motivation along with health beliefs, attitudes to sleep difficulties, perception of the impact of OSA, plus benefits/acceptability of CPAP. This information drives what intervention is likely to be more effective such as cognitive behavioural therapy compared with motivational interviewing or other management. The last model is often underutilised with a tendency to overlook the social/cultural/ educational/socioeconomic status factors that impact the individual and his/her family. The components of each model vary greatly amongst patients, which enables health professionals to target the area that is proving to be the most difficult to overcome or is unrecognised by the patient. Assessing coping styles, daytime sleepiness, self-efficacy, personality and relationship/intimacy through questionnaire data can steer current and future treatments. Other researchers have suggested aspects of such a model as useful constructs for improving adherence, but this more encompassing approach has specific guidelines and examples that can easily be explored by clinicians.

\section{Section II}

This section explores various behavioural treatment interventions used to increase adherence and includes psychosocial interventions, cognitive behavioural therapy (CBT), motivational interviewing (MI), standard care and educational programmes and combined treatments. The role of partners can be an integral and significant factor in this process.

\section{Psychosocial Interventions for CPAP Adherence}

A growing body of research has identified the role of psychosocial factors in CPAP adherence, which are predominantly based on Bandura's social cognitive theory (SCT) [39, 40]. The fundamental perspective is based on self-efficacy and the belief in the individual's ability to maintain a treatment in the face of adversity (side effects) by acknowledging and making it work. Additional components of this model include risk perception of the disorder, outcome expectancies of the treatment process and the coping mechanisms the individual is able to use [41-43].

Two influential questionnaires explored these components, the Ways of Coping questionnaire [43] and the Self-efficacy Measure in Sleep Apnea (SEMSA) by Weaver and colleagues [44]. CPAP users were remarkably inaccurate in linking risk factors and symptoms such as daytime sleepiness and being depressed with untreated OSA, and only two thirds recognised the benefits of using CPAP [44]. Other researchers using the SEMSA $[45,46]$ found self-efficacy and outcome expectations were the most significant factors in CPAP adherence at 3 months, and AHI moderated the daily response in subjective improvements and benefits of CPAP [45]. The timing of measuring self-efficacy to predict adherence is of interest. A number of studies have advocated the assessment of self-efficacy after both education and 1 week of using CPAP [41, 42, 46, 47] whereas other researchers [48, 49••] found that baseline assessment prior to either education or the experience of CPAP predicted adherence at 1 month and 6 months. This raises the question of whether self-efficacy can be increased due to the experience of using CPAP or whether vicarious learning through using videos of "real-life" CPAP users to 
show naïve CPAP users' treatment possibilities can be effective at baseline as Richards and Bartlett were able to do.

\section{Cognitive Behavioural Therapy for CPAP Adherence}

Cognitive behavioural therapy (CBT) was introduced to the CPAP adherence domain in a randomised controlled trial pilot study in 2001 in older adults with severe OSA [50]. This oneon-one intervention contained two 45-min sessions, with not only specific OSA/CPAP information but also goal setting, troubleshooting, treatment expectations and how to obtain help. Initially, there was no difference at 1 week and 4 weeks; however, by 12 weeks, the intervention group was using CPAP for $3.2 \mathrm{~h}$ more compared with the control group. An extension of this study [51] which added the components of self-efficacy, decisional balance and motivational enhancement along with standard care at 1 week had fewer dropouts at 13 weeks. Group-delivered CBT, which measured self-efficacy/social support, was effective in moderate-to-severe OSA patients compared with treatment as usual (TAU) [48]. Partners were encouraged to attend and the intervention was delivered prior to CPAP titration. The CBT group used CPAP for $2.9 \mathrm{~h}$ more than the TAU group, and had higher scores of self-efficacy and social support with significantly fewer individuals not initiating CPAP after their titration study.

\section{Motivational Interviewing for CPAP Adherence}

The Health Belief Model highlights the associated cues for individuals in their decision to initiate CPAP and continue despite difficulties. Work by Olsen and colleagues [52] identified health cues, partner cues and health professional cues as key motivational factors. Further research by this group [53] explored a motivational interviewing intervention with healthy lifestyles in relation to e.g. diet/exercise and to increase positive expectations of change and what that will do to enhance the individual's life. Three sessions of prescriptive motivational interviewing were delivered to newly diagnosed OSA patients with follow-up at 1, 2, 3 and 12 months. The intervention group used their CPAP for an additional $1.5 \mathrm{~h}$ compared with the control group. Study approaches can also change perspective across time such as a pilot CBT study [50] which was later expanded into a motivational interviewing model.

\section{Standard Care and Educational Programmes for CPAP}

What defines standard patient education is difficult to determine as information is often lacking about specific content with little evaluation of effectiveness of programmes or improvements in adherence rates [54]. The modes employed in educational strategies are extremely varied and include slide presentations, videos, general discussion, demonstrations or a talk. Timing of the delivery of CPAP education, i.e. pre- or post-titration, is also important. The initial contact and information session is potentially a primary component in uptake and CPAP adherence. Meurice and colleagues [55] undertook a four-tiered intervention strategy to improve CPAP adherence with "reinforced education programmes" compared with the control or "standard care" in individuals with severe OSA. The reinforced programmes consisted of care from healthcare providers and physicians or physicians alone or healthcare providers alone and contained an increasing number of sessions, which expanded knowledge, understanding and practical components of using CPAP. This reinforced educational approach was associated with $5.6 \mathrm{~h}$ of CPAP use per night at 3 and 6 months and $5.8 \mathrm{~h}$ at 12 months. Sawyer and colleagues [28] suggest this group were high-rate CPAP users contributing to the long-term high adherence; however, the frequency of the "booster sessions" appears a more likely factor reinforcing CPAP maintenance/usage. Relatively simple interventions such as a video explaining OSA/CPAP and treatment benefits result in an increased likelihood of patients returning for follow-up compared with the control group which is critical in good clinical care [56].

The use of telephone-linked communication devices (TLC) introduced to assess CPAP use which act as an educational gobetween for patients was not initially effective, but in a larger follow-up study, self-efficacy and decisional balance were significant factors in this process $[57,58]$. Telehealth measures (pre-programmed automated responses via a telephone-linked communication device) had merit in identifying non-adherers and increasing adherence at 12 weeks [59]. A "health buddy" system which enabled Internet basic treatment support and feedback to be available also did not show statistical significance [60]. However, these interventions are likely to be critical components of future management strategies as they are less labour intensive and have potential merit for individuals without immediate social support [28].

\section{Combined Interventions}

These interventions combine a number of strategies to improve adherence. Work by Hoy and colleagues [61] compared standard care (acclimatisation to CPAP during the daytime, one night in the laboratory, phone calls and clinical visits) with a strong educational input to an intensive support programme (standard care plus education in CPAP users' homes; two additional nights of CPAP in the laboratory and home visits by nurses at four follow-up times). This intervention showed a significant 1.6-h increase in adherence at 6 months but was very labour intensive and expensive. Another multidimensional approach based on forming good daily strategies for using CPAP (cued with relaxation music) found differences at 1 month but not at 3 and 6 months [62] highlighting the need to have strategies that are sustainable across time. 
A review of educational, clinical support or behavioural change approaches to improve CPAP adherence showed that most interventions used on average a combination of four behavioural change techniques [63] with a minimum of one technique and a maximum of nine. There was a moderate effect (Cohen's $d$ 0.52) of all interventional studies examined in terms of promoting nightly CPAP use in treatment-naïve patients. Studies with a focus on behavioural change had higher effect sizes than either clinical or educational support approaches highlighting the importance of integrating behavioural components into CPAP management programmes. Similarly, a systematic review of 30 randomised, parallelgroup studies using educational, supportive and behavioural strategies to increase CPAP use showed that most studies combined components from more than one type of intervention [64]. Compared with standard care, all three types of interventions increased CPAP use in patients with moderateto-severe OSA and new to CPAP. Behavioural therapy showed the largest effect with $1.44 \mathrm{~h}$ of additional CPAP use per night with a larger proportion of patients using their machines for $>4 \mathrm{~h}$ per night; however, there was considerable variation in the effect of the intervention across studies.

\section{The Role of Partners in CPAP Adherence}

The presence or absence of a partner is important to CPAP adherence. Living with a partner increases CPAP usage compared with no partner [65], and usage increased if the bedpartner's sleep improved [66]. Interestingly, Baron and colleagues [14] found spousal involvement, joint problem solving and encouragement to keep using CPAP were not significant adherence factors at 3 months but having no spousal involvement was associated with non-adherence. Golay and colleagues [67] included spouses/partners in their 1-day educational programme increasing adherence from $4.4 \mathrm{~h}$ at baseline to $5.1 \mathrm{~h}$ at 3 months. Although this increased usage was not significant (possibly reflecting the small sample size), partner participation may have been a positive factor. Richards and colleagues [48] found partner participation did not increase adherence within the group receiving CBT, but social support was significant compared with the control group. Inclusion of spouses/ partners in educational programmes is possibly an indirect method of improving adherence. Lower socioeconomic status and being male also appeared to be significant factors of non-adherence. Interestingly, individuals who varied their bedtimes by $>75$ min were more likely to be unmarried and non-adherent at 1 month [68]. Overall, the role of the immediate social environment and important close relationships appear to be positive significant factors in adherence [46].

\section{Section III}

Here, we review the behavioural interventions to improve CPAP adherence which have emerged in the last 3 years and explore their impact and practicality.

\section{Emerging Behavioural Interventions to Improve CPAP Adherence}

An electronic literature search was conducted using the Scopus, PubMed and Medline databases to identify studies (1) reporting the results for randomised clinical trials (RCT) of behavioural interventions designed to improve CPAP adherence in OSA patients and (2) published in the last 3 years (i.e. from 1 January 2013 to 31 March 2016). In each database, the following keywords were used: "CPAP Adherence" AND "Obstructive Sleep Apnea". The search was limited to include full-text and English language publications. The combined databases yielded a total of 276 publications. Publications were excluded if they (1) did not focus on behavioural interventions, (2) did not include a randomised control arm and (3) did not include adult subjects. After filtering the selection, 12 publications were selected and are outlined in Table 1.

\section{Psychosocial Interventions for CPAP}

Interventions designed to target psychosocial factors identified in SCT have met with some success in improving CPAP adherence. A brief motivational enhancement education programme plus standard care increased CPAP with improved treatment self-efficacy and daytime sleepiness at 3 months compared with standard care alone [74]. Deng and colleagues [75] found a 3-month staged matched intervention (health action process approach model) increased CPAP adherence, self-efficacy, outcome expectancy and risk perception at follow-up compared to the standard care. However, these studies did not use a time-matched standard care control and assessment of which aspect(s) of the interventions were responsible for improvements is less clear. The considerable variation in "standard care" across studies adds to the complexity when comparing the effectiveness of the specific content, timing and mode of delivery of different behavioural interventions.

Using a time-matched social interaction control group, Bartlett and colleagues [49••] found a single SCT/CBT session did not increase CPAP adherence nor did it increase self-efficacy. However, there were fewer dropouts in the SCT/CBT group compared with standard care. Interestingly, one point higher on the self-efficacy scale predicted an hour more of CPAP adherence at 6 months. Higher self-efficacy at baseline may define those individuals who require less support emphasising the importance of both high and low scores in CPAP adherence [45, 46]. Aloia and colleagues [76••] 


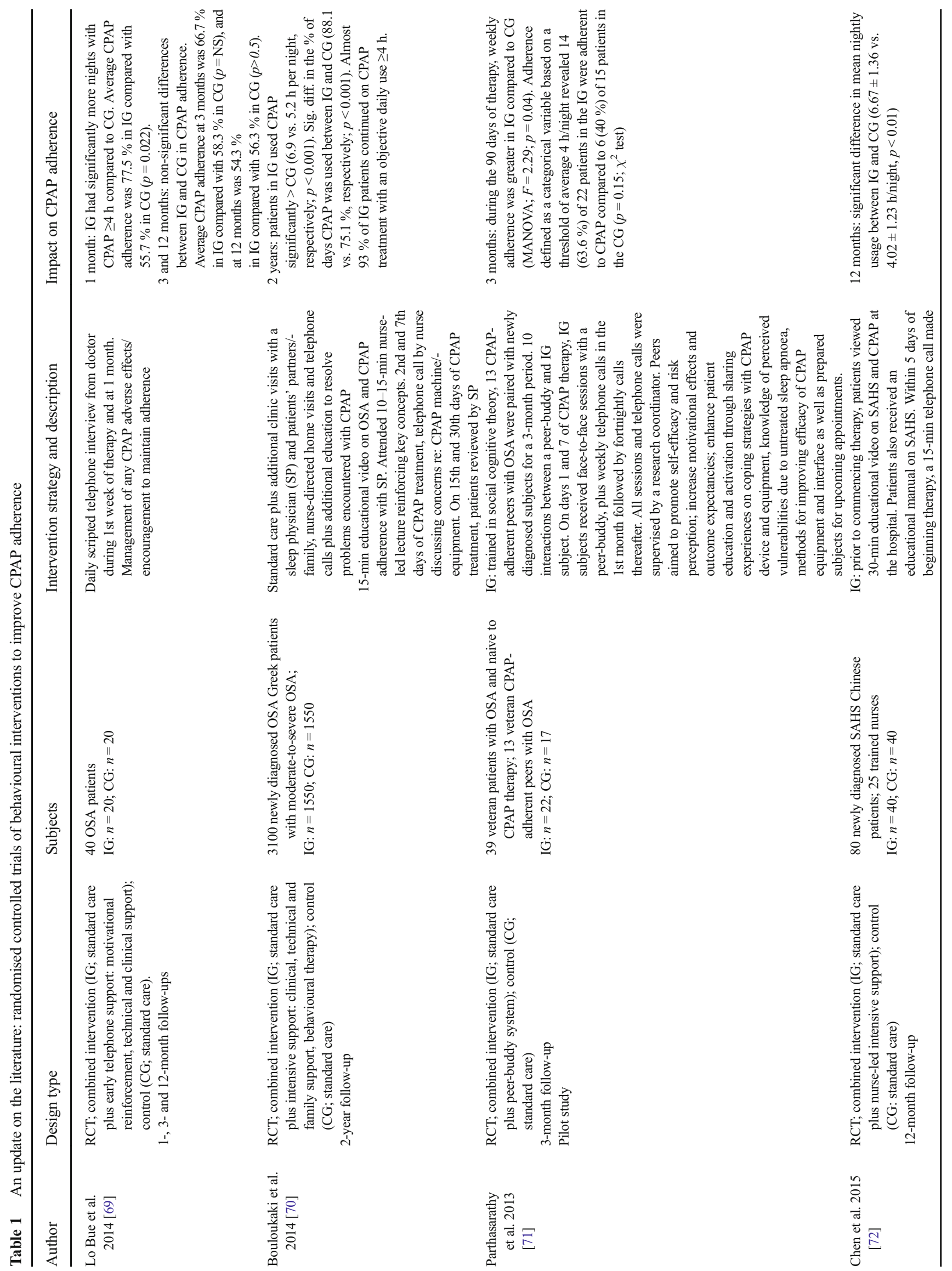




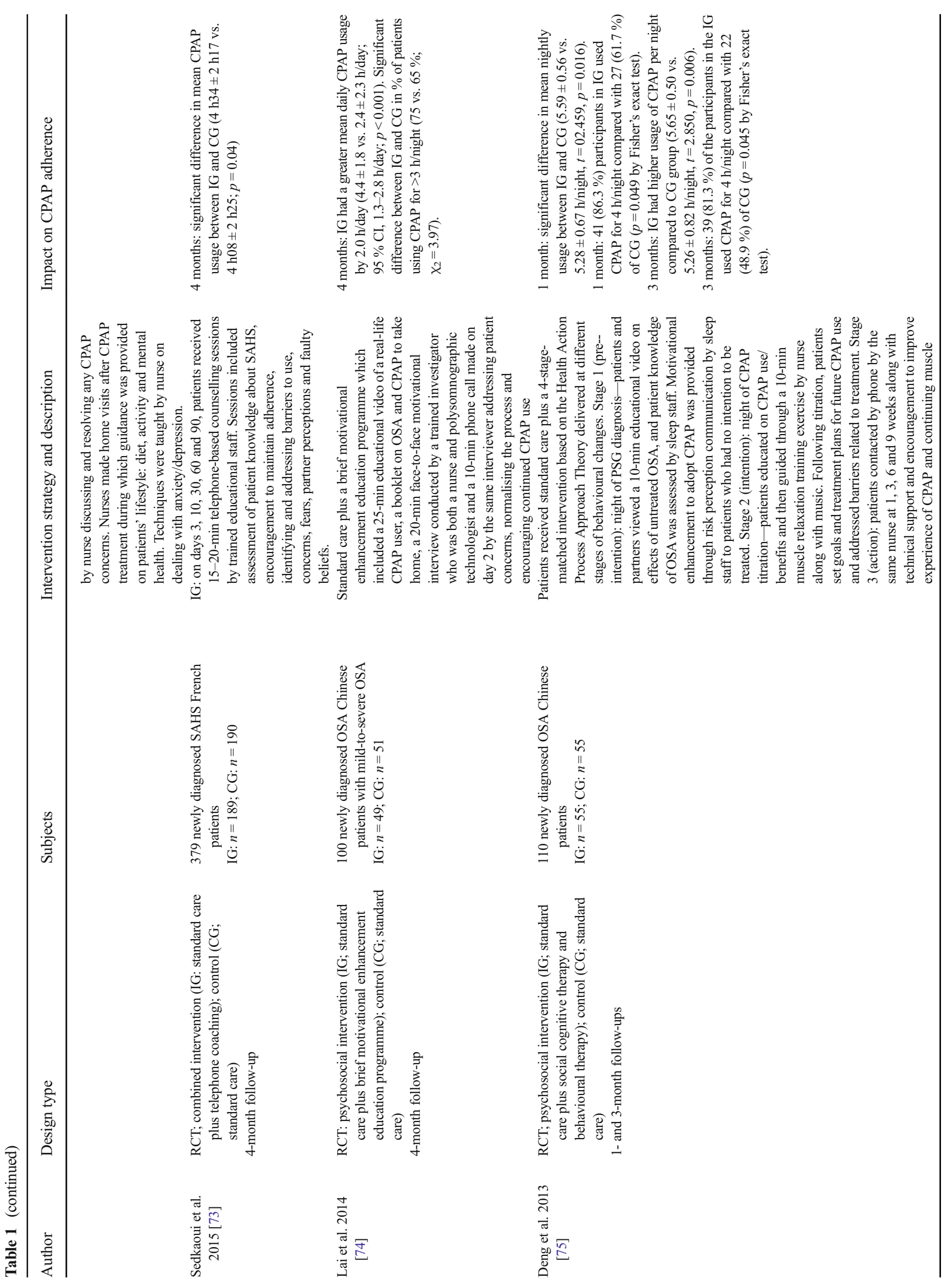




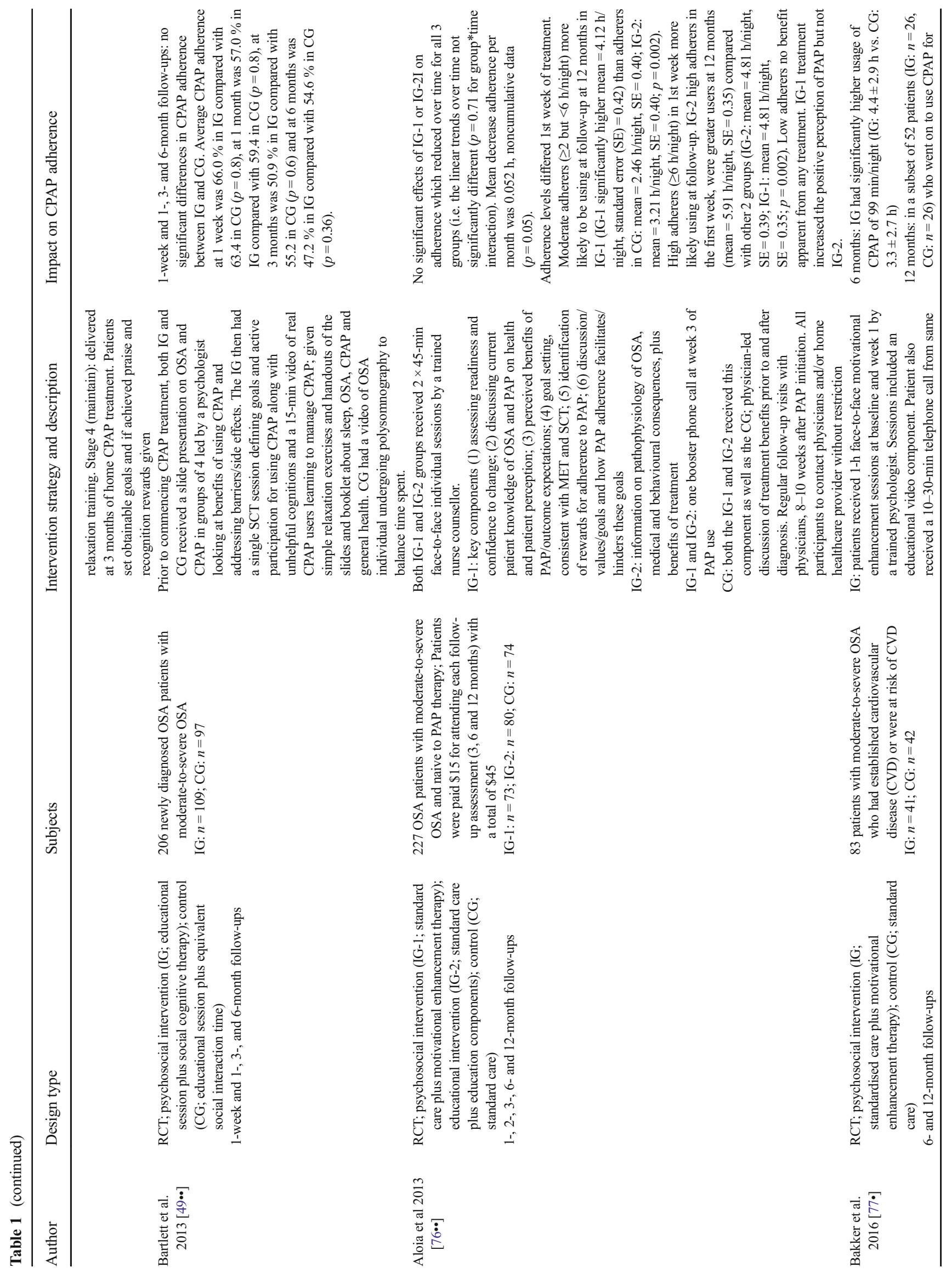




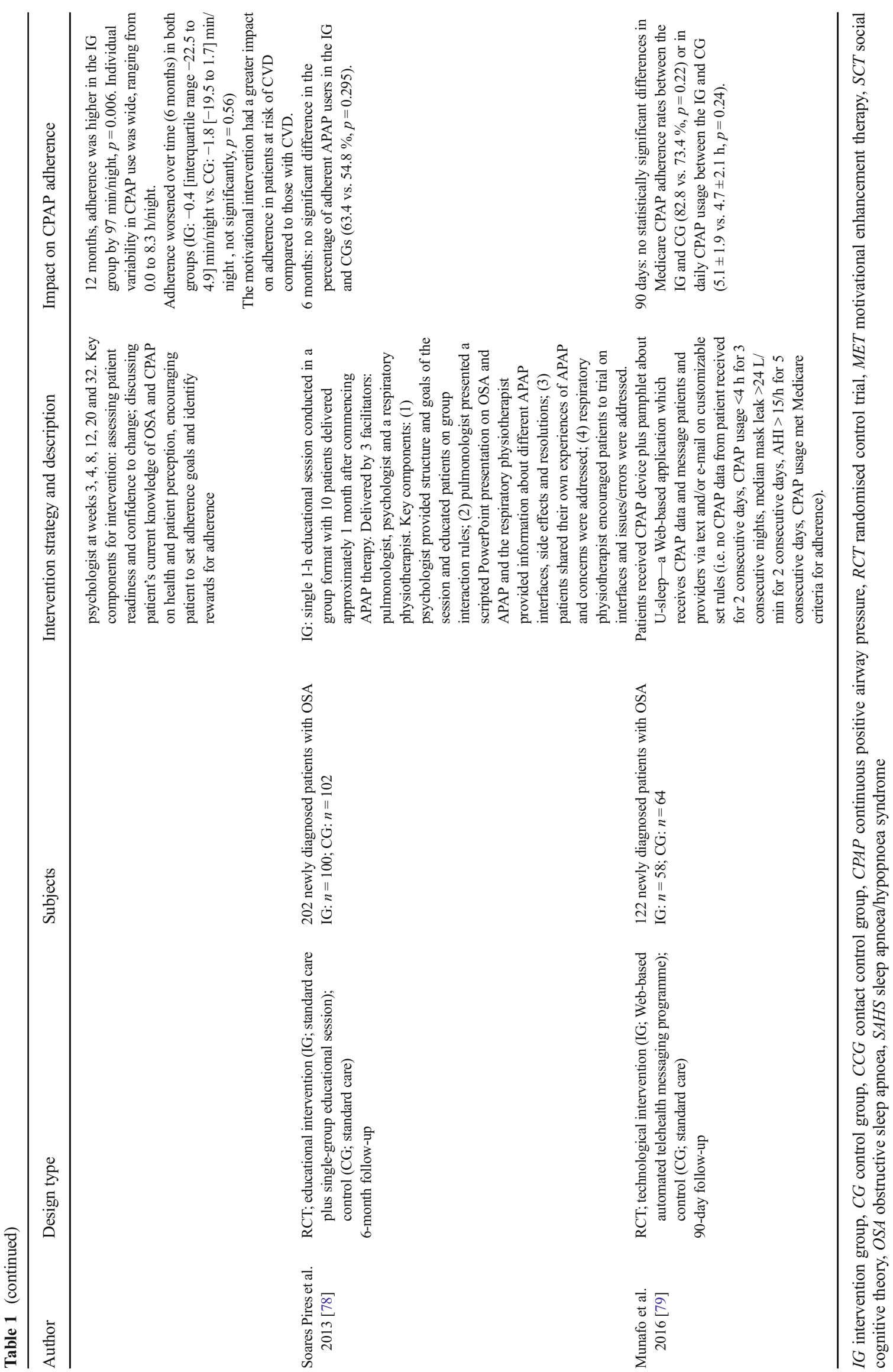


conducted a three-arm randomised controlled trial comparing the effects of an education intervention, a motivational enhancement intervention and standard care on CPAP adherence over a 12-month period. Adherence declined over time for all three groups with no differences in adherence. Stratifying participants into subtypes based on adherence (i.e. low, moderate or high users) during the first week of CPAP therapy prior to the intervention revealed some interesting adherence patterns at follow-up: moderate users were more likely to adhere if they received motivational enhancement, high users were more likely to adhere if in the educational intervention and low users did not benefit from any intervention tested. Profiling patients into subtypes prior to treatment may again allow for the delivery of targeted interventions that optimise best outcomes for patients whilst permitting appropriate allocation of resources in the most cost-effective way [76••, 80].

In moderate-to-severe OSA patients who either were at risk or had cardiovascular disease, a motivational enhancement intervention increased adherence by $1.5 \mathrm{~h}$ per night at both 6- and 12-month follow-ups compared to standard care [77•]. This behavioural intervention sought to resolve ambivalence and boost confidence towards regularly using CPAP each night and though very effective was labour intensive with 1 -h one-on-one sessions at baseline and at 1 week then $6 \times 10-30$-min follow-up phone calls with a psychologist. Patients were selected on the basis of being able to tolerate wearing a CPAP mask (without the device) prior to enrolment. When analysing patterns of CPAP nightly use, adherence decreased across the treatment period and was not different between groups. Motivational enhancement overall was more effective at increasing adherence in OSA patients at risk of cardiovascular disease supporting targeted treatment approaches for optimal intervention(s) in particular subgroups.

\section{Combined Interventions for CPAP}

Combined interventions use a variety of strategies to improve adherence. Treatment may include sharing peer success stories, group education and/or support. This combined approach takes into account the multifactorial nature of CPAP adherence and diversity amongst patients [28, 81, 82].

Sedkaoui and colleagues [73] tested a telephone-based counselling programme containing an education and support component which was delivered by qualified staff during the first 3 months of CPAP therapy, which resulted in greater adherence at 4 months compared to standard care. A minimum of $3 \mathrm{~h}$ per night CPAP was the criteria for adherence (French national health system minimum for reimbursement). The inconsistency in how CPAP adherence is defined across studies, i.e. 3 vs. $4 \mathrm{~h}$ per night, confounds the interpretations of findings.

Lo Bue and colleagues [69] found early telephone support by a sleep physician during the first week of CPAP therapy and at 1 month resulted in better adherence during the first month of therapy compared with standard care. However, these beneficial effects of early support were not maintained past the 1-month time frame. Support during the initial phases of CPAP therapy helps to optimise adherence; however, maintaining and reinforcing treatment to sustain these positive effects are essential [83].

In a 90-day Web-based telehealth intervention providing feedback via text message and/or emails, CPAP usage was not significantly different to standard care which involved five follow-up calls. However, this telehealth programme did significantly reduce health professional time to achieve similar CPAP adherence as standard care, an important option given the increasing pressure on healthcare services [79]. A single 1-h group session of educational and supportive strategies 1 month after starting autotitrating CPAP did not significantly increase adherence compared to a control group [78]. The delayed timing may explain the lack of benefit. Again, secondary analysis of the data found improved adherence in subgroups of patients, e.g. males, non-sleepy and younger patients, highlighting the importance of selecting patients for targeted interventions.

Bouloukaki and colleagues [70] demonstrated how a more intensive support programme increased CPAP adherence at 2year follow-up compared with standard care. In contrast to work by Lo Bue [69] and Sedkaoui [73], this study incorporated a multidisciplinary team approach where not only CPAP nurses and sleep physicians were involved in the delivery of both telephone and face-to-face support but patients' partners and/or family members were required to attend all follow-up care activities, again highlighting the importance of family support and involvement [28, 84]. Another nurse-led intensive intervention resulted in higher CPAP use compared to a standard care programme at 1-year follow-up [72], and similar to Bouloukaki [70], this intervention involved both telephone and face-to-face support. Having a constant health professional to work with is likely to be an important component of nurse-led interventions over time.

In a pilot study [71], the effects of a peer-driven intervention were explored where military veteran "peer buddies" (effective CPAP adherers) counselled and supported naive CPAP users via telephone calls along with two 45-min face-to-face sessions. Over 3 months, this intervention improved CPAP adherence compared to the standard care control group. The small sample size was a limitation and extending the study to 3 months or longer would clarify its effectiveness.

\section{Key Messages from the Recent Literature}

1. Self-efficacy assessment prior to education and/or experience of CPAP may identify those individuals who are more at risk of not taking up CPAP or dropping out - need for more intensive support for these individuals. 
2. Stratifying patients during the first week may also be helpful, and high users may only require an educational intervention compared with moderate users who responded more to motivational interviewing.

3. Examining long-term adherence patterns and how nightly CPAP use changes over time may provide greater insight into the best type of follow-up care/booster sessions required for individuals.

\section{Conclusion/Discussion}

In reviewing the literature relating to behavioural interventions, one key finding is the lack of standardisation in the approaches employed to improve CPAP adherence, making it difficult to identify the most effective components [63]. When interventions are introduced without a theoretical basis, then replication is difficult as there is little foundation for future growth. Stepnowsky and colleagues discuss how a theory helps to describe relationships amongst variables whilst a model may contain a number of theories to explain a problem or disorder. The use of a theory-based approach for behavioural change allows for a more objective assessment of the intervention's effectiveness and the frequency with which it is used [85]. However, of concern is the small number of actual empirical studies published on adherence compared with reviews and theoretical-related models. Systematic reviews of interventional studies showed that behavioural therapy led to large increases in CPAP use compared to usual care and educational and supportive interventions; however, evidence was low-quality due to the wide variability in the intervention effect between studies [64]. Another ongoing problem is the balance of educational information and encouragement to persevere. The categories "Provide general information", "Provide instruction", "Provide information on consequences" and "Provide general encouragement" were the top four components identified in Stepnowsky's recent review of 29 psychoeducational interventions designed to increase CPAP use [63]. Surprisingly, only 9 of the 29 studies provided feedback to patients despite compliance and efficacy data being readily available from the CPAP's in-built monitoring technology. Like Stepnowsky, we have also found that sharing this information with patients and providing ongoing feedback and encouragement at follow-up are important. Optimal timing of the intervention is an important consideration-delivery is usually limited to when most individuals are just starting CPAP, and booster sessions to support long- term nightly use of what is often a lifelong treatment, though necessary, are rarely ongoing.

Individualised health tracking through the use of Webbased and smartphone apps is likely to play a more prominent role in delivering future CPAP interventions and in providing behavioural feedback and measuring effectiveness, with online CBT shown to be effective in the treatment of insomnia [86]. Recently, severe OSA patients who regularly used a mobile health technology app "APPnea" aimed at promoting self-monitoring of treatment had higher CPAP adherence [87]. Studies addressing the choice of interventions that best match individual patient needs/characteristics are likely to be more effective and cost efficient. Efforts to better understand the risk profile of non-adherence [80] are an important step to optimising treatment effects. How other important factors such as length of OSA exposure, psychological factors, disease severity and symptomology, and co-morbidities mediate and moderate the individual response to uptake and adherence of CPAP remains to be elucidated. Greater understanding of individual responses to treatment and how they may change over time remain topics for future research.

\section{Compliance with Ethical Standards}

Conflict of Interest Angela L. D'Rozario, Yael Galgut and Delwyn J. Bartlett declare that they have no conflict of interest.

Human and Animal Rights and Informed Consent This article does not contain any studies with human or animal subjects performed by any of the authors.

\section{References}

Papers of particular interest, published recently, have been highlighted as:

- Of importance

-• Of major importance

1. Marshall NS, Wong KKH, Liu PY, Cullen SRJ, Knuiman MW, Grunstein RR. Sleep apnea as an independent risk factor for allcause mortality: The Busselton Health Study. Sleep. 2008;31(8): 1079-85.

2. Bearpark H, Elliott L, Grunstein R, Cullen S, Schneider H, Althaus $\mathrm{W}$, et al. Snoring and sleep apnea. A population study in Australian men. Am J Respir Crit Care Med. 1995;151(5):1459-65.

3. Young T, Palta M, Dempsey J, Skatrud J, Weber S, Badr S. The occurrence of sleep-disordered breathing among middle-aged adults. N Engl J Med. 1993;328(17):1230-5.

4. Peppard PE, Young T, Barnet JH, Palta M, Hagen EW, Hla KM. Increased prevalence of sleep-disordered breathing in adults. Am J Epidemiol. 2013;177(9):1006-14.

5. Kendzerska T, Mollayeva T, Gershon AS, Leung RS, Hawker G, Tomlinson G. Untreated obstructive sleep apnea and the risk for 
serious long-term adverse outcomes: a systematic review. Sleep Med Rev. 2014;18(1):49-59.

6. Punjabi N. The epidemiology of adult obstructive apnea. Proc Am Thorac Soc. 2008;5:136-43.

7. Bradley TD, Floras JS. Obstructive sleep apnoea and its cardiovascular consequences. Lancet. 2009;373(9657):82-93.

8. Tasali E, Ip MS. Obstructive sleep apnea and metabolic syndrome: alterations in glucose metabolism and inflammation. Proc Am Thorac Soc. 2008;5(2):207-17.

9. Hoyos C, Sullivan D, Liu P. Effect of CPAP on the metabolic syndrome: a randomised sham-controlled study. Thorax. 2013;68(6):588-9.

10. Schroder C, O'Hara R. Depression and obstructive sleep apnea (OSA). Ann Gen Psychiatry. 2005;4(1):13.

11. Young T, Blustein J, Finn L, Palta M. Sleepiness, driving and accidents: sleep-disordered breathing and motor vehicle accidents in a population-based sample of employed adults. Sleep. 1997;20(8): 608-13.

12. George CF. Sleep apnea, alertness, and motor vehicle crashes. Am J Respir Crit Care Med. 2007;176(10):954-6.

13. Swanson LM, Arnedt J, Rosekind MR, Belenky G, Balkin TJ, Drake C. Sleep disorders and work performance: findings from the 2008 National Sleep Foundation Sleep in America poll. J Sleep Res. 2011;20(3):487-94.

14. Baron KG, Smith TW, Berg CA, Czajkowski LA, Gunn H, Jones CR. Spousal involvement in CPAP adherence among patients with obstructive sleep apnea. Sleep and Breathing. 2011;15(3):525-34.

15. Melehan K, Hoyos C, Yee B, O'Meagher S, Hamilton G, Mclachlan R, Ng M, Grunstein R, Liu P. CPAP use improves sexual function in men with OSA and erectile dysfunction (ED): a randomised controlled study. Sleep Biol Rhythms. 2014; 12(Suppl. 1):2.

16. Sullivan C, Issa F, Berthon-Jones M, et al. Reversal of obstructive sleep apnoea by continuous positive airway pressure applied through the nares. Lancet. 1981;I:862-5.

17. McDaid C, Griffin S, Weatherly H, Duree K, van der Burgt M, van Hout $\mathrm{S}$, et al. Continuous positive airway pressure devices for the treatment of obstructive sleep apnoea-hypopnoea syndrome: a systematic review and economic analysis. Health Technol Assess. 2009;13(4):iii-iv. xi-xiv, 1-119, 143-274.

18. Kritikou I, Basta M, Vgontzas AN, Pejovic S, Fernandez-Mendoza J, Liao D, et al. Sleep apnoea and the hypothalamic-pituitaryadrenal axis in men and women: effects of continuous positive airway pressure. Eur Respir J. 2016;47(2):531-40.

19. Arnardottir ES, Lim DC, Keenan BT, Maislin G, Benediktsdottir B, Juliusson $\mathrm{S}$, et al. Effects of obesity on the association between long-term sleep apnea treatment and changes in interleukin-6 levels: The Icelandic Sleep Apnea Cohort. J Sleep Res. 2015;24(2):14859.

20. Antic NA, Catcheside P, Buchan C, Hensley M, Naughton MT, Rowland S, et al. The effect of CPAP in normalizing daytime sleepiness, quality of life, and neurocognitive function in patients with moderate to severe OSA. Sleep. 2011;34(1):111-9.

21. Peppard P, Szklo-Coxe M, Hla K, Young T. Longitudinal association of sleep-related breathing disorder and depression. Arch Intern Med. 2006;166:1709-15.

22. Weaver T, Maislin G, Dinges D, Bloxhan T, George C, Greenberg $\mathrm{H}$, et al. Relationship between hours of CPAP use and achieving normal levels of sleepiness and daily functioning. Sleep. 2007;30: 711-9.

23. Engleman H, Wild M. Improving CPAP use by patients with the sleep apnea/hypopnea syndrome (SAHS). Sleep Med Rev. 2003;7: 81-99.

24. Budhiraja R, Parthasarathy S, Drake CL, Roth T, Sharief L, Budhiraja P, et al. Early CPAP use identifies subsequent adherence to CPAP therapy. Sleep. 2007;30(3):320-4.
25. Kribbs NB, Pack AI, Kline LR, Smith PL, Schwartz AR, Schubert NM, et al. Objective measurement of patterns of nasal CPAP use by patients with obstructive sleep apnea. Am Rev Respir Dis. 1993;147(4):887-95.

26. Engleman HM, Martin SE, Douglas NJ. Compliance with CPAP therapy in patients with the sleep apnoea/hypopnoea syndrome. Thorax. 1994;49(3):263-6.

27. Reeves-Hoche MK, Meck R, Zwillich CW. Nasal CPAP: an objective evaluation of patient compliance. Am J Respir Crit Care Med. 1994;149(1):149-54.

28. Sawyer AM, Gooneratne NS, Marcus CL, Ofer D, Richards KC, Weaver TE. A systematic review of CPAP adherence across age groups: clinical and empiric insights for developing CPAP adherence interventions. Sleep Med Rev. 2011;15(6):343-56.

29. Stradling JR, Davies RJ. Is more NCPAP better? Sleep. 2000;23 Suppl 4:S150-3.

30. Zimmerman M, Arnedt JT, Stanchina M, Millman R, Aloia M. Normalization of memory performance and positive airway pressure adherence in memory-impaired patients with obstructive sleep apnea. Chest. 2006;130:1772-8.

31. Campos-Rodriguez F, Pena-Grinan N, Reyes-Nunez N, De la CruzMoron I, Perez-Ronchel J, De la Vega-Gallardo F, et al. Mortality in obstructive sleep apnea-hypopnea patients treated with positive airway pressure. Chest. 2005;128(2):624-33.

32. Anderson FE, Kingshott RN, Taylor DR, Jones DR, Kline LR, Whyte KF. A randomized crossover efficacy trial of oral CPAP (Oracle) compared with nasal CPAP in the management of obstructive sleep apnea. Sleep. 2003;26(6):721-6.

33. Nilius G, Franke KJ, Domanski U, Schroeder M, Ruhle KH. Effect of APAP and heated humidification with a heated breathing tube on adherence, quality of life, and nasopharyngeal complaints. Sleep Breath. 2016;20(1):43-9.

34. Bachour A, Vitikainen P, Maasilta P. Rates of initial acceptance of PAP masks and outcomes of mask switching. Sleep Breath. 2016;20(2):733-8.

35. Chasens ER, Pack AI, Maislin G, Dinges DF, Weaver TE. Claustrophobia and adherence to CPAP treatment. West J Nurs Res. 2005;27(3):307-21.

36. Edmonds JC, Yang H, King TS, Sawyer DA, Rizzo A, Sawyer AM. Claustrophobic tendencies and continuous positive airway pressure therapy non-adherence in adults with obstructive sleep apnea. Heart Lung. 2015;44(2):100-6.

37. Dickerson SS, Akhu-Zaheya L. Life changes in individuals diagnosed with sleep apnea while accommodating to continuous positive airway pressure (CPAP) devices. Rehabil Nurs. 2007;32(6): 241-50.

38. Crawford MR, Espie CA, Bartlett DJ, Grunstein RR. Integrating psychology and medicine in CPAP adherence-new concepts? Sleep Med Rev. 2014;18(2):123-39.

39. Bandura A. Social learning theory. Englewood Cliffs, NJ: Prentice Hall; 1977.

40. Bandura A. Human agency in social cognitive theory. Am Psychol. 1989;44(9):1175-84.

41. Aloia M, Arnedt JT, Stepnowski C. Predicting treatment adherence in obstructive sleep apnea using principles of behaviour change. $\mathrm{J}$ Clin Sleep Med. 2005;1:346-53.

42. Stepnowsky C, Marler M, Ancoli-Israel S. Determinants of nasal CPAP compliance. Sleep Med. 2002;3:239-47.

43. Stepnowsky Jr CJ, Bardwell WA, Moore PJ, Ancoli-Israel S, Dimsdale JE. Psychologic correlates of compliance with continuous positive airway pressure. Sleep. 2002;25(7):758-62.

44. Weaver T, Maislin G, Dinges D, Younger J, Cantor C, McCloskey $\mathrm{S}$, et al. Self efficacy in sleep apnea: instrument development and patient perceptions of obstructive sleep apnea risk, treatment benefit and volition to use continuous positive airway pressure. Sleep. 2003;26:727-32. 
45. Baron KG, Berg CA, Czajkowski LA, Smith TW, Gunn HE, Jones CR. Self-efficacy contributes to individual differences in subjective improvements using CPAP. Sleep Breath. 2011;15(3):599-606.

46. Sawyer AM, Canamucio A, Moriarty H, Weaver TE, Richards KC, Kuna ST. Do cognitive perceptions influence CPAP use? Patient Educ Couns. 2011;85(1):85-91.

47. Olsen S, Smith S, Oei T, Douglas J. Health belief and model predicts adherence to CPAP before experience with CPAP. Eur Respir J. 2008;32:710-7.

48. Richards D, Bartlett D, Wong K, Malouff J, Grunstein R. Increased adherence to CPAP with a group cognitive behavioural treatment intervention: a randomized trial. Sleep. 2007;30:635-40.

49.• Bartlett D, Wong K, Richards D, Moy E, Espie CA, Cistulli PA, et al. Increasing adherence to obstructive sleep apnea treatment with a group social cognitive therapy treatment intervention: a randomized trial. Sleep. 2013;36(11):1647-54. This study showed that self-efficacy measured at baseline helps to select those individuals requiring more support and follow-up.

50. Aloia MS, Di Dio L, Ilniczky N, Perlis ML, Greenblatt DW, Giles DE. Improving compliance with nasal CPAP and vigilance in older adults with OAHS. Sleep Breath. 2001;5(1):13-21.

51. Aloia M, Smith K, Arnedt JT, Milman R, Stanchina M, Carlisle C, et al. Brief behavioral therapies reduce early positive airway pressure discontinuation rates in sleep apnea syndrome: preliminary findings. Behavorial Sleep Medicine. 2007;5(2):89-104.

52. Olsen S, Smith S, Oei T, Douglas J. Cues to starting CPAP in obstructive sleep apnea: development and validation of the cues to CPAP use questionnaire. J Clin Sleep Med. 2010;6:229-37.

53. Olsen S, Smith SS, Oei TP, Douglas J. Motivational interviewing (MINT) improves continuous positive airway pressure (CPAP) acceptance and adherence: a randomized controlled trial. J Consult Clin Psychol. 2012;80(1):151-63.

54. Epstein LJ, Kristo D, Strollo Jr PJ, Friedman N, Malhotra A, Patil $\mathrm{SP}$, et al. Clinical guideline for the evaluation, management and long-term care of obstructive sleep apnea in adults. J Clin Sleep Med. 2009;5(3):263-76

55. Meurice JC, Ingrand P, Portier F, Arnulf I, Rakotonanahari D, Fournier E, et al. A multicentre trial of education strategies at CPAP induction in the treatment of severe sleep apnoeahypopnoea syndrome. Sleep Med. 2007;8(1):37-42.

56. Jean Wiese H, Boethel C, Phillips B, Wilson JF, Peters J, Viggiano T. CPAP compliance: video education may help! Sleep Med. 2005;6(2):171-4.

57. DeMolles DA, Sparrow D, Gottlieb DJ, Friedman R. A pilot trial of a telecommunications system in sleep apnea management. Med Care. 2004;42(8):764-9.

58. Sparrow D, Aloia M, Demolles DA, Gottlieb DJ. A telemedicine intervention to improve adherence to continuous positive airway pressure: a randomised controlled trial. Thorax. 2010;65(12): 1061-6.

59. Smith CE, Dauz ER, Clements F, Puno FN, Cook D, Doolittle G, et al. Telehealth services to improve nonadherence: a placebocontrolled study. Telemed J E Health. 2006;12(3):289-96.

60. Taylor Y, Eliasson A, Andrada T, Kristo D, Howard R. The role of telemedicine in CPAP compliance for patients with obstructive sleep apnea syndrome. Sleep Breath. 2006;10(3):132-8.

61. Hoy C, Vennelle R, Kingshott R, Engleman H, Douglas N. Can intensive support improve continuous positive airway pressure use in patients with the sleep apnea/hypopnea syndrome? Am J Respir Crit Care Med. 1999;159:1096-100.

62. Smith C, Dauz E, Clements F, Werkowitch M, Whitman R. Patient education combined in a music and habit-forming intervention for adherence to continuous positive airway (CPAP) prescribed for sleep apnea. Patient Educ Couns. 2009;74(2):184-90.

63. Stepnowsky C, Zamora T, Edwards C, Liu L, Agha Z. Interventions to improve CPAP adherence and outcomes: role of theory and behavioral change techniques. J Sleep Disorders Ther. 2013;2(133):2167-0277.1000133.

64. Wozniak DR, Lasserson TJ, Smith I. Educational, supportive and behavioural interventions to improve usage of continuous positive airway pressure machines in adults with obstructive sleep apnoea. Cochrane Database Syst Rev. 2014;1:Cd007736.

65. Lewis KE, Seale L, Bartle IE, Watkins AJ, Ebden P. Early predictors of CPAP use for the treatment of obstructive sleep apnea. Sleep. 2004;27(1):134-8.

66. McArdle N, Kingshott R, Engleman H, MacKay T, Douglas N. Partners of patients with sleep apnoea/hypopnoea syndrome: effect of CPAP treatment on sleep quantity and quality of life. Thorax. 2001;56:513-8.

67. Golay A, Girard A, Grandin S, Métrailler J-C, Victorion M, Lebas $\mathrm{P}$, et al. A new educational program for patients suffering from sleep apnea syndrome. Patient Educ Couns. 2006;60(2):220-7.

68. Sawyer AM, King TS, Sawyer DA, Rizzo A. Is inconsistent pretreatment bedtime related to CPAP non-adherence? Res Nurs Health. 2014;37(6):504-11.

69. Lo Bue A, Salvaggio A, Isidoro SI, Romano S, Marrone O, Insalaco G. Usefulness of reinforcing interventions on continuous positive airway pressure compliance. BMC Pulm Med. 2014;14: 78.

70. Bouloukaki I, Giannadaki K, Mermigkis C, Tzanakis N, Mauroudi $\mathrm{E}$, Moniaki V, et al. Intensive versus standard follow-up to improve continuous positive airway pressure compliance. Eur Respir J. 2014;44(5):1262-74.

71. Parthasarathy S, Wendel C, Haynes PL, Atwood C, Kuna S. A pilot study of CPAP adherence promotion by peer buddies with sleep apnea. J Clin Sleep Med. 2013;9(6):543-50.

72. Chen X, Chen W, Hu W, Huang K, Huang J, Zhou Y. Nurse-led intensive interventions improve adherence to continuous positive airway pressure therapy and quality of life in obstructive sleep apnea patients. Patient Prefer Adherence. 2015;9:1707-13.

73. Sedkaoui K, Leseux L, Pontier S, Rossin N, Leophonte P, Fraysse $\mathrm{JL}$, et al. Efficiency of a phone coaching program on adherence to continuous positive airway pressure in sleep apnea hypopnea syndrome: a randomized trial. BMC Pulm Med. 2015;15:102.

74. Lai AY, Fong DY, Lam JC, Weaver TE, Ip MS. The efficacy of a brief motivational enhancement education program on CPAP adherence in OSA: a randomized controlled trial. Chest. 2014;146(3):600-10.

75. Deng T, Wang Y, Sun M, Chen B. Stage-matched intervention for adherence to CPAP in patients with obstructive sleep apnea: a randomized controlled trial. Sleep Breath. 2013;17(2):791-801.

76.• Aloia MS, Arnedt JT, Strand M, Millman RP, Borrelli B. Motivational enhancement to improve adherence to positive airway pressure in patients with obstructive sleep apnea: a randomized controlled trial. Sleep. 2013;36(11):1655-62. This study showed that stratifying CPAP users based on adherence in the first week will further identify those who are struggling and guide their future treatment.

77. Bakker JP, Wang R, Weng J, Aloia MS, Toth C, Morrical MG, et al. Motivational enhancement for increasing adherence to CPAP: a randomized controlled trial. Chest. 2016. This study shows that different interventional approaches are required for those with other significant health issues and also examined night-to-night CPAP adherence over time.

78. Soares Pires F, Drummond M, Marinho A, Sampaio R, Pinto T, Goncalves M, et al. Effectiveness of a group education session on adherence with APAP in obstructive sleep apnea - a randomized controlled study. Sleep Breath. 2013;17(3):993-1001.

79. Munafo D, Hevener W, Crocker M, Willes L, Sridasome S, Muhsin M. A telehealth program for CPAP adherence reduces labor and yields similar adherence and efficacy when compared to standard of care. Sleep Breath. 2016;20(2):777-85. 
80. Sawyer AM, King TS, Hanlon A, Richards KC, Sweer L, Rizzo A, Weaver TE. Risk assessment for CPAP nonadherence in adults with newly diagnosed obstructive sleep apnea: preliminary testing of the Index for Nonadherence to PAP (INAP). Sleep Breath. 2014: 1-9.

81. Lettieri CJ, Williams SG, Collen JF. OSA syndrome and posttraumatic stress disorder: clinical outcomes and impact of positive airway pressure therapy. Chest. 2016;149(2):483-90.

82. Weaver T, Grunstein R. Adherence to continuous positive airway pressure therapy: the challenge to effective treatment. Proc Am Thorac Soc. 2008;5:173-8.

83. Sin DD, Mayers I, Man GC, Pawluk L. Long-term compliance rates to continuous positive airway pressure in obstructive sleep apnea: a population-based study. Chest. 2002;121(2):430-5.
84. Ye L, Malhotra A, Kayser K, Willis DG, Horowitz JA, Aloia MS, et al. Spousal involvement and CPAP adherence: a dyadic perspective. Sleep Med Rev. 2015;19:67-74.

85. Painter JE, Borba CP, Hynes M, Mays D, Glanz K. The use of theory in health behavior research from 2000 to 2005: a systematic review. Ann Behav Med. 2008;35(3):358-62.

86. Espie CA, Kyle SD, Miller CB, Ong J, Hames P, Fleming L. Attribution, cognition and psychopathology in persistent insomnia disorder: outcome and mediation analysis from a randomized placebo-controlled trial of online cognitive behavioural therapy. Sleep Med. 2014;15(8):913-7.

87. Isetta V, Torres M, Gonzalez K, Ruiz C, Dalmases M, Embid C, Navajas D, Farre R, Montserrat JM. A new mHealth application to support treatment of sleep apnoea patients. J Telemed Telecare. 2015. doi: $10.1177 / 1357633 \times 15621848$. 